A LIVELY ELECTRONIC COMPENDIUM OF RESEARCH, NEWS, RESOURCES, AND OPINION

Astronomy Education Review

Volume 6, Aug 2007 - Mar 2008

Issue 2

\title{
Instruction as a Scientific Experiment: A Professional Development Case Study of a Professor Changing the Introductory Astronomy Course for Non-Science Majors
}

\author{
by Erik Brogt \\ University of Arizona \\ Received: 09/09/07, Revised: 10/15/07, Posted: 11/28/07
}

The Astronomy Education Review, Issue 2, Volume 6:20-31, 2008

(C) 2007, Erik Brogt. Copyright assigned to the Association of Universities for Research in Astronomy, Inc.

\begin{abstract}
This article describes a case study of a faculty member who wanted to change his introductory astronomy course for non-science majors to include more learner-centered pedagogy. To help him achieve this goal, he was assisted by an instructional specialist and the author. The professor approached the overhaul of instructional style as a scientific experiment. Using interview and observation data, the motivations and expectations of this professor and the implementation of the professional development are explored. Results indicate that persuading science faculty to view their teaching as a scientific experiment or research project may be a valuable avenue for professional development. Results hint that professional development for faculty can benefit from professional developers who are also well vested in the content area taught.
\end{abstract}

\section{INTRODUCTION}

In American universities, the notion of academic freedom and the tenure system allow faculty to choose the curriculum and instructional methods that they personally favor for their courses. This means that they can also change the content or their teaching strategies if they so choose. In this study, one astronomy professor did exactly that. Dissatisfied with the results of his teaching, he decided to completely overhaul his course and introduce learner-centered pedagogy, grounded in astronomy education research, into his introductory non-science-major astronomy classroom. He adopted an existing course from a colleague who is well known for his teaching quality in the department. This colleague has been using learner-centered and research-based pedagogy in his introductory astronomy classroom for years. The professor decided to use his colleague's course as-is, including homework, in-class activities, PowerPoint presentations, exams, and grading scheme, and to make only modest changes. The course had a heavy emphasis on the text Lecture-Tutorials for Introductory Astronomy (Prather, Slater, Adams, Bailey, Jones, 
\& Dostal 2004; Adams, Prather, \& Slater 2005), which was the main interactive element during class periods and a source for assessment questions. At the faculty member's request, an instructional specialist from the department and I were assigned to his section to fulfill the dual roles of teaching assistant and professional developer.

In this qualitative study, I describe the professional development process of this professor and explore his motivations to change and his expectations of the course. The study focuses on four main points:

1. What are the professor's motivations for changing the way he is teaching?

2. What are his initial expectations for the course?

3. Were those expectations met at the end of the semester?

4. How did the professor see his professional development, and how did he feel about it?

This article is set up as follows: In Section 2, I outline the research setting and methodology, findings are given in Section 3, and conclusions are drawn in Section 4.

\section{METHODOLOGY}

\subsection{Participants, Positionality, and Setting}

\subsubsection{Participants and Positionality}

This study had three main participants. The first participant was an assistant professor in the astronomy department who had taught introductory astronomy for non-science majors four times. The second participant was an instructional specialist in the astronomy department who assists faculty in improving their teaching. To facilitate reading, I will use the pseudonyms Mark (assistant professor) and Edna (instructional specialist). I could be considered a third participant in this study. I worked closely with Edna in the two years prior to this study and was a teaching assistant for the colleague whose course Mark adopted. As such, I was very familiar with the classroom environment of that course, and with the educational materials (lecture-tutorials, homework, and assessments used) and the pedagogy behind them.

My positionality in this setting was twofold. I was the assigned teaching assistant for Mark's class. As such, it was my responsibility to be in class every day, help students with questions, assist during activities, and perform various supporting duties outside class (e.g., grading, maintaining the course Web site, and holding office hours ). At the same time, I shared the responsibility with Edna to mentor Mark in improving his overall teaching. I was constantly wearing two hats in the classroom.

\subsubsection{Setting of the Study}

The research was conducted in a large Research I institution in the southwest United States. The introductory astronomy course at this university is a large-enrollment three-unit course aimed at non-science majors. Typically, a single section enrolls 150 students, mostly freshmen and sophomores. The course satisfies the lower-division general education science requirement at this university. A section is usually taught by one instructor and one full-time ( 20 hours per week) graduate teaching assistant (TA). In addition, an undergraduate homework grader was assigned to our section, and one of my responsibilities was to supervise this undergraduate grader. 
Mark's course was taught in the fall of 2005 in a large auditorium with tiered rows that seats about 200 people. Three aisles, two on each side of the room and one in the center, allow access to the front, where the instructor usually lectures and where the controls for the computer, LCD projector, and various audiovisual equipment are located. The setting allows the instructor and TAs to freely move about the room and reach the majority of students relatively easily, which is useful when students have questions during in-class activities. Classes were taught twice a week for 75 minutes per class period over a 16-week semester.

\subsection{Data Collection}

In this study, semistructured interviews, logs, and observations were used as data sources. I interviewed Mark twice, once at the beginning of the semester and once at the end, and Edna once, about six weeks into the semester. I formally observed Mark's classroom once and took field notes. For other classes, I wrote in a log book after class. In this log, I noted educational events that occurred during that class period. Data collection for this study was originally conducted in the fall of 2005 as two separate class projects for me. Because I had not initially intended to publish the results, no approval for the project was sought from the Institutional Review Board. Retroactive approval from the Institutional Review Board was obtained in the summer of 2007 in accordance with policies to use the data for research purposes (Brogt, Dokter, \& Antonellis 2007), and consent was received from the participants to use the data as such.

\subsubsection{Interviews}

The semistructured interviews with Mark focused mostly on his motivations to change his classroom and on his expectations for his teaching experience and anticipated student learning. The interview with Edna focused on her role as an experienced professional developer and on classroom events. The general line of questions can be found in Appendixes A-C. Because of the exploratory nature of this study, I cast a wide net on the motivational aspects, and the interview questions were rather broad. They were meant more to paint an overall picture of the motivational issues and experiences of the faculty member rather than focusing directly on specific aspects of motivation. As the semester went along, patterns emerged, and the second interview became more focused. Each individual interview was audiotaped and lasted approximately 20 minutes.

\subsubsection{Observations}

Although I was in every class over the semester and kept a teaching log of events (see section 2.2.3), I also conducted formal observations in Mark's class once. This means that rather than being the teaching assistant and being actively engaged with student learning, I focused on the actions of the instructor and took extensive notes. The observation took place at the end of September, about one month into the semester.

Even though I was formally observing, I still assisted, albeit in a lessened capacity, with interactive elements in class, like the lecture-tutorials. In that sense, I was more a participant-observer than a fly-on-the-wall observer in this setting. It was mentioned to the students at the beginning of the class period that I would not be participating as much because of my research responsibilities. The protocol for the observations can be found in Appendix D. The observations were a way to get a better understanding of the learning environment that Mark had created for the course. 
During the observation, I jotted down field notes on events that occurred in the classroom, with specific attention to instructor-student interactions and motivational cues from the instructor. Because I had to help students during the interactive elements, and I did not want them to be able to understand what I had written on my notepad should they accidentally read it, I wrote all the field notes in my native language, Dutch. Although this turned out to be somewhat exhausting (having to mentally switch between two languages at a rapid pace), I felt that it was the best way to ensure data confidentiality.

\subsubsection{Log Book Notes}

After each class, I made notes in a log book on events that had occurred. These were primarily used to give Mark feedback each week. Because I wanted to express my thoughts freely, and given the rather sensitive nature of some of the comments, they were again written in Dutch rather than English.

\subsection{Analysis Procedures}

The interviews were transcribed verbatim the week after each interview had taken place and analyzed for trends. Because of the broad scope of the interviews, a lot of information was not directly related to the primary research questions. The log book notes and the observation provided information that was used to sketch an overall picture of the educational setting and to provide context to the interview responses. This triangulation lessened the risk of misinterpreting meaning in the interview data (Eco 1992). The responses to the interview questions were divided into three categories based on the four focus points for the study. The first category consisted of all remarks referring to the motivation to change the teaching style, the second consisted of all remarks referring to the expectations for the class at the beginning of the semester, and the third consisted of all remarks referring to whether those expectations were met at the end of the semester, and general reflective comments. The log book notes were used primarily as part of Mark's professional development. However, they were also analyzed for trends (recurring events) in this study to identify difficulties in the professional development (personal consultation in this case) that may need more attention in future similar projects.

\section{FINDINGS}

\subsection{Motivations, Expectations, and Views at the Beginning of the Semester}

\subsubsection{Motivation to Change}

In the first interview, Mark indicated that he was frustrated with the way his teaching had gone in the past. He was dissatisfied with the outcomes of his course because he felt students were not understanding the material as well as he had hoped. He signaled problems with the way his course was set up and the mismatch of the curriculum with the non-science-major audience.

As I went through my textbook I ended up covering just exactly, despite my approach and my frame of reference, I ended up doing a survey course in introductory astronomy. And that happened twice, so that was very disappointing and I could see myself doing it but almost couldn't stop myself. 
It was this observation in himself that led him to change course: "So I thought, well, let's try a fundamentally different approach, a kind of a reset button to just radically change what I was doing and see if this wouldn't be better."

Mark also observed that obtaining assistance in changing his course from professional developers who also know the content can be useful: "You [Edna and I] both are, and have been at various levels, yourselves instructors [of introductory astronomy], but you're at least thinking enough about it that you bring unique perspectives to it" because the faculty are not really trained for this: "[the department of astronomy and the university in general] have experts in the content area, but you certainly don't have experts in the delivery of that content."

Mark's motivation and willingness to invest much time and effort into changing his class was noted by Edna. According to her, virtually no external pressures (from the department, college, or university) are present to motivate change in teaching practices. All motivation has to come from within the faculty member teaching. And even then, change is not without potential risk to the career. Edna noted,

In a Research I institution you're almost perceived as not caring when you care too much about your instruction. Because what you're supposed to care about is your research and so if you're spending too much time on your teaching, you're not spending enough time on your research, or your research isn't important enough to spend time on.

In summary, Mark showed dissatisfaction with his previous teaching. He decided to invest time and energy in seeking out professional development to improve his teaching from people he considered experts in content delivery.

\subsubsection{Initial Expectations}

As Mark decided to dramatically change his teaching strategy, his overarching goals were an increased depth of understanding and relevance of the material to the students' daily lives. As he noted,

I will cover less material, by definition. One third of the stuff that's just absolute factoids that I cover will be less and I think that that's already a great plus. My expectations then are, with that decrease in content, I expect a requisite depth of understanding, or that's my hope in the broadest possible terms.

My main interest is that they get a basic understanding of a few physical principles that are general enough that they could be expected to be applied in their daily lives.

Mark did express some reservations about using someone else's course as-is, without knowing all the details behind the choices for the material.

I am sort of an accepting vessel of this material so far and so I don't feel I'm in control yet of the materials. I don't know what to pull out, I don't know what to add in.

I would have done the curriculum differently, but I don't think it is so important. In the overall scheme, I think that this course has a great probability to be better than the one I used to teach. Even though I would change it at the $20 \%$ level is my guess. I would take different material, I would try to do it in any way that is the same way that these materials are presented, but I would have changed the topics that I would cover in the course. 
In summary, Mark expected to cover less material but also expected that students would be able to have a deeper understanding of the material. Because the course that he taught was adopted from someone else, he did not feel in control. He did not know the ideas behind the individual elements in the course, making it harder for him to adapt the material to his own wishes.

\subsubsection{Mark's Initial View about Changing His Course}

In his first interview, Mark also hinted that he saw changing the way the course was taught as an experiment: "[By] actually doing this exercise ... I personally feel like I'm going to improve my teaching skills in a way that I hadn't foreseen doing in these past five years or in the next five years, so for me, this is a real laboratory teaching." This view was corroborated by Edna, who stated in her interview,

He's approaching it much more like a scientist. And so, he takes advice from you [the author] and me to heart as experts. He treats us as experts. That doesn't mean that he, you know, out of hand agrees with everything that we say, because he doesn't. I mean, there are definitely cases where he'll, he'll argue with us about a research study or about the how or why of something, and he's looking for a research-driven response. He wants to know that data's been collected on someone that says that we should do something a certain way.

Edna further commented that she thought that because Mark was convinced by the data, he felt that he had to change his course in order to be the best possible instructor for his students.

The thing that makes Mark the most different from any single faculty member that I have ever worked with, in that he's approaching his instruction from a scientific perspective. [He has] seen data that shows [him] that [he] can teach better, that there are materials, that there are ways of teaching that will increase student learning. And he's decided that, for whatever reason, that he'd ought to believe the research and given that he's a scientist he's been provided with data that he's decided to believe and so he must make change. Because not making change would [make him consider himself to] be neglectful on his part as an instructor.

In summary, Mark approached his instruction like he would approach his science research. He was interested in the data and feedback that Edna and I provided, and he followed up on suggestions for improvement. He was also willing to argue the evidence presented to him, just like he would in a science research project.

\subsection{Observations}

Although I was in class as a teaching assistant every day, only once did I do formal observations. During the class that was observed, the structure was as follows. Both Mark and Edna spent the 15 minutes before class talking to students and walking up and down the aisles to engage students in brief conversations. In these conversations, they used student-type language. In his instruction, Mark also used informal language when possible, rather than more formal physics jargon. About 45 minutes into the classroom period, which up until then had been lecture, the class broke into pairs to complete a lecture-tutorial (Adams, Prather, \& Slater 2005), the Socratic dialogue-driven activity to help students confront their misconceptions about a particular topic (in this case, Kepler's laws of planetary motion). The instructors (Mark, Edna, and I) helped student pairs who raised their hands if they got stuck with the questions. Most of the students were engaged and active, which could be noted by the level of noise in the classroom and the overheard 
conversations among the students, which mostly dealt with the questions at hand. The lecture-tutorials were run according to a known model of successful implementation (see Brogt 2007 for details) and lasted about 20 minutes, with one break about 10 minutes in, when a large fraction of the students were struggling with the same question. At that point, Mark brought the class back together and addressed that question, after which pair work was resumed. It was noted that Mark spent considerable time (up to several minutes) trying to explain things to pairs of students during the lecture-tutorial, whereas Edna did not spend much time with students (typically under 20 seconds). She usually asked students to explain their thinking and did not give straight answers, but rather asked questions. After the lecture-tutorial, Mark answered a few general questions on the activity. He urged the students to come to office hours if they felt that they hadn't understood the material so well. The class period ended after this.

\subsection{Coaching}

Mark, Edna, and I agreed on various nonverbal cues with which Edna or I could alert Mark to certain events in class. The two most commonly used were a signal to pick up speed in the lecture, and a signal to not go into elaborate detail in class in response to a student question but rather to ask the student to come by after class or come to office hours. When Edna or I felt that Mark went too fast for the students, based on our previous experiences with these types of classes, we would raise our hand and ask a question as if we were a student, knowing that it was a question that most students at that point would have but for some reason did not want to ask. Edna typically also wrote notes during class on educational events. I wrote a teaching $\log$ after each class period but normally did not write notes during class. We compared the notes prior to giving Mark feedback to make sure that we did not miss something significant.

Once every week, Edna, Mark, and I sat down to give Mark detailed feedback on his teaching and to prepare the lectures for the coming week. Typically, Edna and I would meet before this to determine what to bring up and how. As mentioned, Mark treated his teaching like a scientific experiment, and in that sense, Edna and I were the data collectors who showed him the results of the experiment. Mark typically asked us to back up our comments to him with data from educational research.

Mark indicated at the end of the semester that he was very excited by the experience of the professional development:

I can't imagine that a teacher would get anywhere near the instructional support and critical feedback and learning experiences on how to teach that I have through this process. I mean, I think there's just no comparison. I have been given the gift of a free semester-long working tutorial in how to teach [introductory astronomy].

However, Mark also indicated that he sometimes felt that he had to accept pedagogical arguments and educational data on authority, rather than being able to explore it for himself:

Although I'm encouraged [by Edna and the author] to make a final call [on curricular and instructional issues], because that is my job and my responsibility, I don't have ready arguments for the reasons that are offered for why one should do it this way. And so I feel at a bit of a disadvantage.

I don't have the background, the time, or the expertise to really question any piece of evidence that I'm given for why something should be done a certain way. And so, I can either follow my instincts, although I'm led to believe that they're rather poor at this point, or I can just take what I've been 
given and execute as I'm told. And I still feel uncomfortable with that arrangement.

In summary, Mark really valued the intensive professional development he received but expressed reservations about the degree to which he felt he could challenge a certain approach advocated by Edna and me.

\subsection{Mark's Postsemester View on Meeting His Expectations}

In the postsemester interview, Mark expressed satisfaction on the course as a whole: "I am happy with how it went. I think there are things that I would do differently next time, but in general I think the semester went well. I'm happy with the results."

He mentioned that he felt he had met about half of his personal goals for the class. He specifically met his goals of getting the students to a more in-depth understanding by covering less material. His goal of emphasizing a few physical concepts and hitting those again and again in class over the semester was not met. He indicated that this was because he adopted someone else's curriculum in which that goal was absent. He indicated that if he taught the course again, this would be one of the changes he would make. Mark said that he felt ambivalent about implementing changes that were not research based.

Again I kept getting this feeling that any suggestion I would make that aren't tested by a 100,000 students weren't of value, so I felt like gosh, I really don't have much to offer here. I basically have to use this as it is.

What I keep telling the students whenever they complain about something is look, we've run a 100,000 students through this curriculum. It is good. We've honed it in this way and I will never be able to affect that for the content I would like to deliver to the students [because I don't have the infrastructure to research my materials methodically]. I just won't ever do it. Unless I can convince a group to undertake that for me and develop those materials for me, I'll never have the chance to implement exactly the kind of content I want with the methodology I've been exposed to and now appreciate. So that kind of drags.

But on the other hand, he felt that if he wanted to change materials, he would do so systematically: "I'd start to tweak at the edges I suppose. I think I'd feel more confident picking and choosing a bit more." In summary, Mark expressed happiness and satisfaction with the course and the professional development but felt that he could not rightfully challenge the methodology and the materials. He also felt that any new materials should live up to the standards he had seen in the materials he used. Because he did not have the research infrastructure or time to develop, validate, and test new materials, he felt ambivalent about changing anything, but he indicated that he would do so if the need arose.

\section{DISCUSSION AND CONCLUSIONS}

Judging from the first interview with Mark and the interview with Edna, it is likely that Mark was strongly motivated by an internal source to change his classroom to foster a deeper student understanding. There are few incentives for faculty to change the method of instruction as dramatically as he did. He chose to seek out professional development and approached changing his instruction as a scientific experiment. This approach meant that Mark valued and relied on data and feedback on his performance. Edna and I served as the sources of data in his experiment. 
The model of approaching teaching as a scientific experiment has certain interesting aspects for professional developers working with faculty. For example, it can improve acceptance of ideas and suggestions offered by the professional developers if these ideas and suggestions are based on research data from the educational literature. A (translated from Dutch) log book entry for September 9, 2005, barely two weeks into the semester, illustrates this: "We [Edna and I] told him how impressed we are with his work ... [he] accepts didactical and pedagogical advice." However, the downside, as illustrated by Mark's feelings of being disadvantaged, is that the faculty cannot look into the "black box" that is educational research; it is not their field of study. The risk becomes that the results from educational research can be used as an argument from authority, which is contrary to the scientific method. It appears to be a fine balance for the professional developer to show the faculty the data and methods that back up the statements, and the realities of a fast-paced college teaching environment, where there may not be time to back up every statement with a crash-course in educational research.

One method of alleviating the possible tension is to create rapport with the faculty, a sine qua non in any professional development project. In this case, I speculate that rapport was facilitated by the fact that both professional developers (Edna and I) had a background in astronomy. This shared background in astronomy created a team sense that was beneficial to the professional development effort. Because Edna and I were familiar with the scientific content of the course being taught, we were able to provide specific feedback on content delivery; this would have been much more difficult if we had no knowledge of the content. Nevertheless, the constraints that Mark felt as a result of his limited choices to shape the curriculum is something to be aware of in future personal consultation professional development projects. In this case, Mark accepted the constraints because he was convinced by the research data that underpinned the classroom environment, and he trusted Edna and me. If those two conditions had not been met, the professional development environment and the subsequent results in the classroom might have been very different.

Obtaining professional development data in class was not always easy because Edna and I were also assisting during the activities. Because of this, we could not always observe in detail the interaction between instructor and students in these activities, which was needed to gauge the instructor's pedagogical style and methods. During the formal observation, when I was not assisting students at the same level as in other classes, data could be obtained from observing Mark that would have otherwise remained unavailable. This is something that should be considered in the model of using professional developers in a teaching assistant role. In this case, it was unavoidable because of the logistics of the department.

The results are consistent with Emerson and Mosteller's (2000) literature review on professional development. They argue that for professional development to be successful, it needs to be collegiate, extensive in time, and focused or concrete.

This study illustrates what can be done and achieved in a situation in which the faculty member is very interested in educational and instructional innovation. The atmosphere between the professional developers and the instructor was collegiate, the professional development lasted the entire semester, and the goals were focused and concrete, dealing with optimizing the educational environment for student learning in specific, concrete instances. Several recent studies have begun to investigate the obstacles to instructional innovation in tertiary education (e.g. Walczyk \& Ramsey 2003; Walczyk, Ramsey, \& Zha 2007; Henderson \& Dancy, in press). Mark's approach to instruction as if it were a research project hints that if other faculty can be persuaded to view their teaching as a research project, chances are that more instructors would be willing to work with professional developers to ensure high-quality teaching. 
Mark has not been scheduled to teach the introductory astronomy course for non-science majors since the semester in which the data for this study were taken. As such, it is not possible at present to conduct a follow-up study on his teaching strategies, motivations, and expectations. He informally said (outside the official data collection in this study), "There is no way I'm going back to the old methods." It would be interesting to see how Mark will teach his next introductory class and to what extent he is comfortable with and willing to use the techniques, skills, and curriculum that he used in this study without the benefit of having of the presence of professional developers. This would give some insights as to the effectiveness of the personal consultation method of professional development that was applied in this study.

\section{Acknowledgment}

The author would like to thank Erin Dokter for her thorough feedback on earlier versions of this manuscript.

\section{References}

Adams, J. P., Prather, E. E., \& Slater, T. F. 2005, Lecture-Tutorials for Introductory Astronomy, Upper Saddle River, NJ: Prentice Hall.

Brogt, E. 2007, "A Theoretical View on a Successful Implementation of Lecture-Tutorials," Astronomy Education Review, 6(1), 50. http://aer.noao.edu/cgi-bin/article.pl?id=243.

Brogt, E., Dokter, E., \& Antonellis, J. 2007, "Regulations and Ethical Considerations for Astronomy Education Research," Astronomy Education Review, 6(1), 43. http://aer.noao.edu/cgi-bin/article.pl?id=242.

Eco, U. 1992, "Overinterpreting Texts," in Interpretation and Over-interpretation, S. Collni (Editor), Cambridge: Cambridge University Press, 45.

Emerson, J. D., \& Mosteller, F. 2000, "Development Programs for College Faculty: Preparing for the Twenty-first Century," Educational Media and Technology Yearbook, 25, 26.

Henderson, C., \& Dancy, M. H. in press, "Barriers to the Use of Research-Based Instructional Strategies: The Influence of Both Individual and Situational Characteristics," Physical Review Special Topics: Physics Education Research, pages forthcoming.

Prather, E. E., Slater, T. F., Adams, J. P., Bailey, J. M., Jones, L. V., \& Dostal, J. A. 2004, "Research on a Lecture-Tutorial Approach to Teaching Introductory Astronomy for Non-Science Majors," Astronomy Education Review, 3(2), 122. http://aer.noao.edu/cgi-bin/article.pl?id=132.

Walczyk, J. J., \& Ramsey, L. L. 2003, "Use of Learner-Centered Instruction in College Science and Mathematics Classrooms," Journal of Research in Science Teaching, 40, 566.

Walczyk, J. J., Ramsey, L. L., \& Zha, P. 2007, "Obstacles to Instructional Innovation According to College Science and Mathematics Faculty," Journal of Research in Science Teaching, 44, 85. 


\section{Appendix A}

Questions for the instructor at the beginning of the semester:

- Why did you decide to change your classroom?

- What do you hope that/want the students (to) get out of the class?

- What do you hope that/want the students (to) get out of the class?

- What do you hope/want to get out of/learn from the class yourself?

- What do you hope/want to get out of the instructional specialist and me?

- What do you look forward to in the class?

- Do you have reservations about the class, and if so, what?

\section{Appendix B}

Questions for the educational specialist:

- Describe your position or role as an educational specialist.

- What is, in your opinion, the main reason that faculty want to change their teaching?

- What is your position in the classroom?

- What do you pay attention to in the class?

- What do you pay attention to outside of class?

- What kind of problems do you typically encounter when helping faculty implement student-centered techniques?

- What are the similarities between the two classes you have been involved in?

- What are the differences between the two classes? (especially level of interaction)

- How does teaching style and personality of the instructor influence (help or hinder) the implementation of learner-centered strategies?

- How do the full professor and the assistant professor adapt to interactive teaching?

\section{Appendix C}

Questions for the postsemester interview with the instructor:

- Can you give me your view on how this semester went?

- Can you compare and contrast this with previous semesters you taught?

- I'd like you to react to several statements you made at the beginning of the semester and to what extent you think those statements still hold and/or whether we accomplished this.

O With a decrease in content, I expect a requisite depth of understanding.

O My main interest is that they get a basic understanding of a few physical principles that are general enough that they could be expected to be applied in their daily lives.

(When talking about what you want to get out of the class) I have no agenda, I am a servant in this class.

$O$ (About teaching this class) I am going to improve my teaching skills in a way that I hadn't 
foreseen: This is real laboratory teaching.

O (About what you had reservations about): I don't feel that I'm in control yet of the materials.

- In summary: in retrospect, would you say your expectations for the class were met?

- What is the most important thing you learned this semester in this class?

- What was the most interesting thing in the class?

- What was the most frustrating thing in the class?

- How would you teach (this course) next time? Would you do things differently and, if so, what?

- We talked this semester about grading on a curve, its merits and drawbacks. How do you feel about grading on a curve now?

\section{Appendix D}

Observing protocol:

O How do the instructor and TA encourage student involvement?

O How do the instructor and TA engage the students?

O How do the instructor and TA assist students who get stuck? Do they ask questions to help students make their thinking explicit?

○ How do the instructor and TA react to different types of students and student questions?

O How do the instructor and TA ensure that students understand the material?

ER

$20-31$ 